\title{
Bor doplu CVD grafen üretimi ve yakıt pili performansı
}

\section{Suha Yazıcı*, F. Gül Boyacı San²}

${ }^{1}$ TUBITAK-MAM, Enerji Enstitüsü, Gebze-Kocaeli, Türkiye, ORCID ID orcid.org/0000-0002-1449-1811 ${ }^{2}$ TUBITAK-MAM, Enerji Enstitüsü, Gebze-Kocaeli, Türkiye, ORCID ID orcid.org/0000-0002-5578-1145

\begin{tabular}{|c|c|}
\hline MAKALE BíLGisí & ÖZET \\
\hline $\begin{array}{l}\text { Makale geçmişi: } \\
\text { İlk gönderi } 18 \text { Temmuz } 2019 \\
\text { Revize gönderi } 03 \text { Eylül } 2019 \\
\text { Kabul } 17 \text { Eylül } 2019 \\
\text { Online } 30 \text { Eylül } 2019\end{array}$ & \multirow{4}{*}{$\begin{array}{l}\text { Kimyasal Buhar Biriktirme (CVD) yöntemiyle üretilen grafen yapıların bor (B), kobalt } \\
\text { (Co)-azot }(\mathrm{N}) \text { - katkı maddeleri ile Proton Elektrolit Membran (PEM) yakıt pillerinde } \\
\text { elektrokatalizör veya destek malzemesi olarak kullanılabilirliği incelenmiştir. Bor } \\
\text { doplamada amonyum boran }\left(\mathrm{H}_{3} \mathrm{~N}^{\left.-\mathrm{BH}_{3}\right)} \text { doğrudan kullanılırken sodyum borhidrür }\right. \\
\left(\mathrm{NaBH}_{4}\right) \text { dolaylı olarak kullanımıştır. Üretilen örnekler elektrokimyasal yöntemler } \\
\text { yanında Taramalı Elektron Mikroskobu (SEM), Geçirimli Elektron Mikroskobu } \\
\text { (TEM), X-ışını Fotoelektron Spektroskopisi (XPS), Raman ve XRD yöntemleri ile de } \\
\text { tanımlanmıştır. Grafen örneklerin elektrokimyasal oksijen indirgeme reaksiyon (ORR) } \\
\text { ölçümleri döner disk elektrot (RDE) yönetimiyle, geliştirilen elektrotların yakıt pil } \\
\text { testleri } 5 \mathrm{~cm}^{2} \text { aktif alanda yakıt pili test sistemi ile yapılmıştır. Bor içerikli indirgeme } \\
\text { yaklaşımı, yakıt pili testlerinde PtCo/B/grafen katalizör ile } 3000 \mathrm{~mA} / \mathrm{cm}^{2} \text { seviyelerinde } \\
\text { diğer yaklaşımların } 3 \text { katı ve üzeri akım yoğunluğu vermiştir. }\end{array}$} \\
\hline Araştırma Makalesi & \\
\hline DOI: 10.30728/boron.593606 & \\
\hline $\begin{array}{l}\text { Anahtar kelimeler: } \\
\text { Bor doplama, } \\
\text { CVD grafen, } \\
\text { Yakıt pili. }\end{array}$ & \\
\hline
\end{tabular}

\section{Production of boron-dopped CVD graphene and fuel cell performance}

\section{ARTICLE INFO}

\section{Articl history:}

Received 18 July 2019

Revised form 03 September 2019

Accepted 17 September 2019

Available online 30 September

2019

Research Article

DOI: 10.30728/boron.593606

\section{Keywords:}

Boron-dopping,

CVD graphene,

Fuel cell. \begin{abstract}
Graphene, produced by chemical vapor deposition (CVD) and modified with boron (B), cobalt (Co) and nitrogen (N), was investigated as electrocatalyst and support material for proton exchange membrane (PEM) fuel cells. Ammonia borane $\left(\mathrm{H}_{3} \mathrm{~N}-\right.$ $\left.\mathrm{BH}_{3}\right)$ was used directly as doping agent while sodium borohydride $\left(\mathrm{NaBH}_{4}\right)$ was used indirectly. Samples were characterized, in addition to electrochemical methods, by scanning electron microscopy (SEM), X-ray photo-electron microscopy (XPS), Raman spectroscopy and XRD. While rotating disc electrodes (RDE) were used to characterize oxygen reduction reaction capacity of graphene electrodes, fuel cell testing was carried out with $5-\mathrm{cm}^{2}$ active area single cell. Boron based reduction of catalysts, compare to other approaches, have resulted 3 times higher current density reaching $3000 \mathrm{~mA} / \mathrm{cm}^{2}$ with $\mathrm{PtCo} / \mathrm{B} / \mathrm{graphene}$ catalyst in fuel cell testing.
\end{abstract}

\section{Giriş (Introduction)}

Yakıt pillerinde kullanılan platinden kaynaklı yüksek katalizör maliyetlerini azaltmak için değişik katalizör malzemeleri geliştirilmektedir. Demir, kobalt gibi malzemeler platin ile alaşım olarak kullanılırken metal olmayan yapıların elektro-katalitik etkisi de önem kazanmıştır. Grafen yapıların, özellikle azot-doplu karbon ve grafit yapıların elektrokimyasal proseslere katkısı araştırılmaktadır [1,2]. Grafen yapısı içerisine farklı şekillerde yerleşen azot atomları oksijen indirgeme reaksiyonunu iyileştirmektedir [3]. Bor doplamanın sensor [4] ve başka alanlardaki uygulamaları üzerine yayınlar vardır [5-8]. Grafen üzerine bor-doplama çoğunlukla grafen oksit (GO) üzerinden kimyasal karıştırma ve ısıl işlem üzerinden yapılmaktadır. Farklı üretim ve doplama yaklaşımları Agnoli vd. (2016) tarafından analiz edilmiştir [9]. Doplamada tek aşamalı [10], 2-aşamalı [11] yaklaşımlar yanında tek atom [12] veya çoklu atom [13-15] doplama yaklaşımları denenmektedir. Bu yaklaşımlarda gaz ile (diboran, boran), sıvı ile (tri-metil borat, tri-etil borat ve tri-propil borat) ve katı ile $\left(\mathrm{B}, \mathrm{B}_{2} \mathrm{O}_{3}\right.$, $\mathrm{BN}$ ve $\left.\mathrm{TiB}_{2}\right)$ doplama örnekleri görülmektedir. Gaz ve sıvı bor kaynakları zehirli ve korozif olduğu için dikkatli olunması gerekir.

Bor doplu grafen ve katalizörlerin yakıt pillerinde kullanımı üzerine sınırlı sayıda çalışma mevcuttur [16]. Çalışmalar neredeyse tamamen alkali elektrolitler üzerinedir. Sheng vd. borun etkilerini alkali $(\mathrm{KOH})$ elektrolitte araştırmışlar, metal içermeyen bu ortamlarda, oksijen kinetiğinin iyileştiğini belirlemişlerdir [12]. B atomlarının yüzey üzerinde elektron verdikleri, bunun 
oksijen adsorpsiyon ve dolayısıyla indirgemeye yardım ederek aktif oldukları düşünülmektedir [17]. Yukarıda bahsedilen çalışmalar alkali ortamlarda üçlü elektrot sistemi çalışmalarıdır. Oksijen indirgenme reaksiyonu alkali ve asit elektrolitlerde aşağıdaki şekilde gerçekleşmektedir:

Asit: $\mathrm{O}_{2}+4 \mathrm{H}^{+}+4 \mathrm{e}^{-} \rightarrow 2 \mathrm{H}_{2} \mathrm{O}$

$\left(\mathrm{O}_{2}+2 \mathrm{H}^{+}+2 \mathrm{e}^{-} \rightarrow \mathrm{H}_{2} \mathrm{O}_{2}\right.$ ve $\left.\mathrm{H}_{2} \mathrm{O}_{2}+2 \mathrm{H}^{+}+2 \mathrm{e}^{-} \rightarrow 2 \mathrm{H}_{2} \mathrm{O}\right)$

Alkali: $\mathrm{O}_{2}+2 \mathrm{H}_{2} \mathrm{O}+4 \mathrm{e}^{-} \rightarrow 4 \mathrm{OH}^{-}$

$\left(\mathrm{O}_{2}+\mathrm{H}_{2} \mathrm{O}^{2}+2 \mathrm{e}^{-} \rightarrow \mathrm{HO}_{2}^{-}+\mathrm{OH}^{-}\right.$ve $\left.\mathrm{H}_{2} \mathrm{O}+\mathrm{HO}_{2}^{-}+2 \mathrm{e}-\rightarrow 3 \mathrm{OH}^{-}\right)(2)$

Asit ortamlarda ara indirgenme basamağı olarak hidrojen peroksit $\left(\mathrm{H}_{2} \mathrm{O}_{2}\right)$ oluşabilmekte, voltaj istenilen değerlerin altında olabilmektedir. Kimyasal yöntemlerle elde edilen grafenin borik asit ile doplanması sonrası $560 \mathrm{~mW} / \mathrm{cm}^{2}$ güçlere ulaşan yakıt pili performansı elde edilmiştir [18]. Bor doplamanın, Pt ve B arasındaki bağı güçlendirdiği bunun yakıt pili performansına pozitif etki yaptığı düşünülmektedir [19]. PtCo katalizör, kimyasal yollarla üretilen grafen ile birlikte elektrokatalizör oksijen indirgeme için test edilmiştir. Pt/grafen yapılara göre PtCo/grafen yapıların daha yüksek oksijen indirgeme akımı verdikleri gösterilmiştir [20]. Metanol ile yapılan elektrokimyasal testlerde de PtCo/grafen yapıların daha yüksek elektro-katalitik aktivite ve ömre sahip oldukları bildirilmiştir [21].

CVD grafen doplama, devamlı-faz yapı kırılmadan gerçekleştirilmek istendiğinden daha farklı yaklaşımlar gerektirmektedir. CVD grafen, doğrudan metanol yakıt pillerinde anot tarafında membran üzerinde bariyer olarak kullanılmış, metanol geçişini engellediği gösterilmiştir [22].

CVD grafenin doğrudan PEM katalizörleri yükleme için yüzey olarak kullanımına literatürde rastlanmadığı için, bu çalışma ile bor ile doğrudan veya dolaylı olarak doplanmış CVD grafen içeren katalizörlerin PEM yakıt pili performansına nasıl etki edeceği araştırılmıştır.

\section{Malzeme ve yöntemler (Material ve methods)}

\subsection{Malzemeler ve kimyasallar (Materials and chemicals)}

CVD grafen büyütmek için alttaş olarak $580 \mu \mathrm{m}$ gözenekli 1,7 mm kalınlığında nikel köpük kullanılmıştır [23-24]. Grafen büyütme sırasında \%99,99 saflıkta argon $(\mathrm{Ar})$, azot $\left(\mathrm{N}_{2}\right)$, hidrojen $\left(\mathrm{H}_{2}\right)$ ve metan $\left(\mathrm{CH}_{4}\right)$ gazları kullanıımıştır. Vakum altında metan gazı beslenerek sıcaklık $\left(1000^{\circ} \mathrm{C}\right)$ ve zaman (5-30 dakika) değiştirilerek büyütülen grafen, nitrik asit $\left(\mathrm{HNO}_{3}\right)$ kullanılarak nikelden (Ni) uzaklaştırıımıştır. Doplama deneylerinde gaz amonyak $\left(\mathrm{NH}_{3}\right)$, amonyum boran $\left(\mathrm{H}_{3} \mathrm{~N}-\mathrm{BH}_{3}\right)$ ve sodyum borhidrür kullanılmıştır. Elektrokimyasal testlerde elektrolit olarak $\mathrm{HClO}_{4}$ kullanılımıştır. Referans katalizör olarak platin/karbon katalizör (HiSPEC $® 3000$, ağ. $\% 20 / C$, Alfa Aesar) kullanılmıştır. Grafen üzerine katalizör yüklemelerinde kloroplatinik asit $\left(\mathrm{H}_{2} \mathrm{PtCl}_{6} \cdot 6 \mathrm{H}_{2} \mathrm{O}\right.$,
Alfa Aesar) ve kobalt klorür ( $\mathrm{CoCl}_{2}$, Alfa Aesar) sülfürik asit $\left(\mathrm{H}_{2} \mathrm{SO}_{4}\right.$, Merck), hidrojen peroksit $\left(\mathrm{H}_{2} \mathrm{O}_{2}\right.$, Alfa Aesar, \%30 su) ve sodyum borhidrür $\left(\mathrm{NaBH}_{4}\right.$, Merck) kullanılmıştır. Yakıt pili deneyleri için DuPont ${ }^{\mathrm{TM}}$ NafionTM XL membranlar kullanılış̧ır. Gaz difüzyon tabakası olarak Sigracet 29BC seçilmiştir. Laboratuvarda üretilen $3 X$ saflıkta de-iyonize su deneylerde ve yıkama işlemlerinde kullanılmıştır.

\subsection{Elektrokimyasal ekipmanlar ve ölçümler (Elect- rochemical equipments and measurements)}

Elektrokimyasal ölçümler, 3-elektrot konfigürasyonunda yapılmış olup, çalışma elektrotu olarak $0,196 \mathrm{~cm}^{2}$ yüzey alanına sahip camsı karbon (glassy carbon) elektrot kullanılmıştır. Platin tel karşı elektrot, doygun kalomel elektrot (SCE) ise referans olarak kullanılmıştır. Deneyler $100 \mathrm{ml}, 0,1 \mathrm{M} \mathrm{HClO}_{4}$ ortamında, oda sıcaklığında asit-membran şartları simule edilerek gerçekleştirilmiştir. Ölçümler, döngülü elektrot (RDE) sistemine bağlı potansiyostat/galvanostat sistemi ile yapılmıştır. Elektrolit çözeltisi ilk olarak oksijen ile doyurulmuş ardından üzerinden beslenerek voltaj-akım sinyalleri gürültüsüz elde edilmiştir. Açık devre voltaj ve döngülü voltametre ölçümleri düzenli olarak alınmıştır. Yakıt pili testleri $5 \mathrm{~cm}^{2}$ aktif alana sahip membran elektrot üniteleri (MEÜ) kullanılarak 20 volt 50 amper kapasiteli sıcaklık, basınç ve gaz debisi kontrollü test istasyonu ile gerçekleştirilmiştir. Testler \%100 nem altında hidrojen ve oksijen gazları kullanılarak gerçekleştirilmiştir. Anot ve katot katalizör yüklemeleri Toray grafit kâğıt (TGP) üzerine $0,66 \mathrm{mg} / \mathrm{cm}^{2}$ dir. Yakıt pili polarizasyon eğrileri, açık devre voltajdan başlayarak her $100 \mathrm{mV}$ düşüşte elde edilen akım 5 dakika sonunda kaydedilerek elde edilmiştir.

\subsection{Karakterizasyon (Characterization)}

Grafen yapıların karakterizasyonu için Taramalı Elektron Mikroskobu (SEM Scanning Electron Microscope, JSM6335-F Oxford Instruments AZTEC-EDS), Geçirimli Elektron Mikroskobu (TEM Transmission Electron Microscope, JEOL 2100 HRTEM), X-ışını Fotoelektron Spektroskopisi (XPS X-ray Photoelectron Spectroscopy), Raman ve XRD (PANalytical X'Pert Pro MPD) yöntemleri kullanılmıştır.

\section{Sonuçlar ve tartışma (Results and discussion)}

Grafen büyütme esnasında ve sonrasında boron bileşiklerinin parçalanması sonucu oluşacak bor ile grafen yapısının doplanması hedeflenmiştir (Şekil 1). Borik asit ve amonyum boran $\left(\mathrm{BH}_{3} \mathrm{NH}_{3}\right)$ ile doplama denemeleri yapılmıştır.

Borik asit tüp fırın içerisine konulduğu zaman $200^{\circ} \mathrm{C}$ civarında yapısındaki su buharlaşmakta, metaborik asit $\left(\mathrm{HBO}_{2}\right)$ denilen beyaz kristal yapı oluşmaktadır. Grafen büyütme sıcaklığına ulaşıldığı noktada asit boron trioksite $\left(\mathrm{B}_{2} \mathrm{O}_{3}\right)$ dönüşerek beyaz kristal yapıda ergimiş 


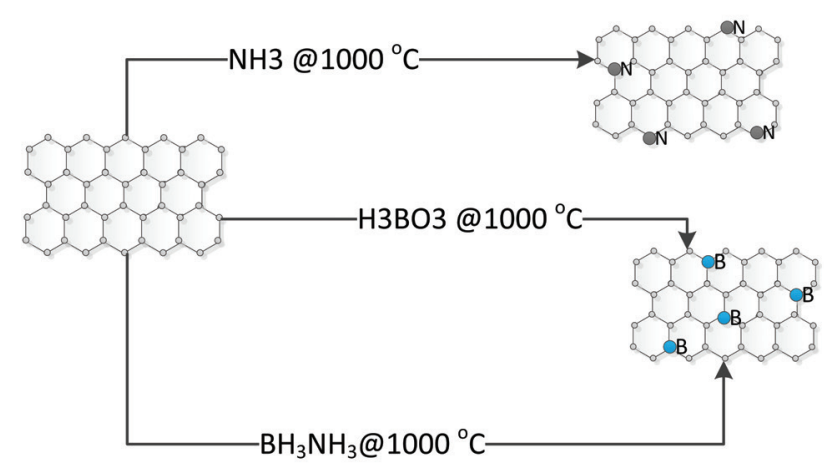

Şekil 1. Azot ve bor doplama için senaryolar (Pathways for nitrogen and boron doping).

olarak kalmaktadır. Illk olarak Şekil 2'de gösterilen grafit örnekler (GDL1 ve Graf7) borik asite batırılarak emdirilmiş daha sonra 20 dakika $1000^{\circ} \mathrm{C}$ de tüp fırında vakum altında ısıl işlem yapılmıştır. Proses sırasında bor buharının aşağıdaki reaksiyonla grafen üzerinde doplu yapı oluşturması beklenmiştir [25]:

$\mathrm{xB}_{2} \mathrm{O}_{3}+(2+3 \mathrm{x}) \mathrm{C}$ (grafen) $\rightarrow 2 \mathrm{~B}_{\mathrm{x}} \mathrm{C}($ grafen $)+3 \mathrm{xCO}$

B-doplu örnekler üzerine ICP-MS (ThermoScientific iCAP RQ) ile yapılan analizlerde bor oranının ağ. $\% 0,07$ oranında olduğu tespit edilmiştir. Şekil 2'de, orijinal örnek (grafit Graf5) ile borik asite batırılmış örneklerin Raman spektroskopilerinde bir farklılık gözlemlenmemiştir. Literatür örneklerinde de Raman spektroskopisi, doplu ve doplu olmayan örneklerindeki farklılıkları göstermede tek başına yeterli olmamaktadır $[11,26]$. Borik asitli örneklerin Raman değişimleri benzer olduğundan doplama olmadığı veya doplamanın spektroskopiyi değiştirmediği sonuçlarına ulaşılmıştır.

Borik asit ile yapılan örneklerde Raman sonuçları bir farklılık göstermediği için farklı yaklaşım olarak doplama için amonyum boran $\left(\mathrm{BH}_{3} \mathrm{NH}_{3}\right)$ kullanılmıştır. Amonyum boranın kullanıldığı durumda, yüksek sıcaklıkta termoliz yoluyla aşağıdaki reaksiyon mekanizmalarının gerçekleşeceği öngörülmüştür [27]:

$$
\begin{aligned}
& \mathrm{nNH}_{3} \mathrm{BH}_{3}(\mathrm{~s}) \rightarrow \mathrm{nNH}_{3} \mathrm{BH}_{3}(\mathrm{l}) \\
& \mathrm{nNH}_{3} \mathrm{BH}_{3}(\mathrm{l}) \rightarrow\left[\mathrm{NH}_{2} \mathrm{BH}_{2}\right]_{\mathrm{n}}(\mathrm{s})+\mathrm{nH}_{2}(\mathrm{~g}) \\
& {\left[\mathrm{NH}_{2} \mathrm{BH}_{2}\right]_{\mathrm{n}}(\mathrm{s}) \rightarrow\left[\mathrm{NHBH}_{\mathrm{n}}(\mathrm{s})+\mathrm{nH}_{2}(\mathrm{~g})\right.} \\
& {\left[\mathrm{NHBH}_{\mathrm{n}}(\mathrm{s}) \rightarrow[\mathrm{NB}]_{\mathrm{n}}(\mathrm{s})+\mathrm{nH}_{2}(\mathrm{~g})\right.}
\end{aligned}
$$

Grafen büyütmenin $1000^{\circ} \mathrm{C}$ gerçekleşmesi düşünülerek amonyum boranın da bu sıcaklığa kadar parçalanacağından hareketle grafen büyütülmüş örnekler, amonyum boran tozu ile birlikte $1000^{\circ} \mathrm{C}$ ' de Isıl işleme tabii tutulmuştur. Prosesin sonunda örnek üzerinde N-B doplamanın birlikte gerçekleşmesi beklenmektedir.

Nikel köpük üzerinde büyütülen grafenin 20 dakika $\mathrm{NH}_{3}$ gazı ( $\mathrm{H}$ numunesi) ve amonyum boran ( $\mathrm{G}$ numunesi) ile doplanması sonrası elde edilen $X$-ray sonuçları Şekil 3'te verilmiştir. Cu X-ışını tüpü $(\lambda=1,5405$ Angstrom) kullanılarak 2 ila 70 derece açıları arasında yapılan ölçümlerde $2 \theta$ açısı $44-45^{\circ}$ ve $52^{\circ}$ pikler vermiştir. Grafen/karbon yapılar $44,55^{\circ}$ 'de pik vermektedir ve burada görülmektedir. $44-45^{\circ}$ ve $52^{\circ}$ 'deki pikler, asit ile yapıdan uzaklaştırılan nikel ile de ilişkili olabilir.

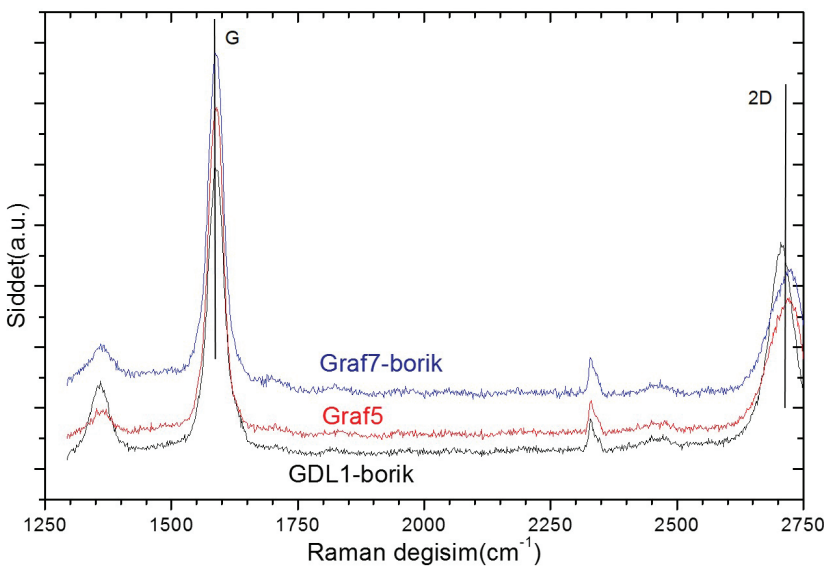

Şekil 2. Grafit (Graf5) ve borik asit'e batırılıp ısıl işlem görmüş gaz difüzyon tabakası (GDL1), grafit (Graf7) Raman spektroskopileri (Raman Spectroscopy results for graphite (Graf5) and boric acid-immersed heat treated gas diffusion layer (GDL1) and graphite (Graf7)).

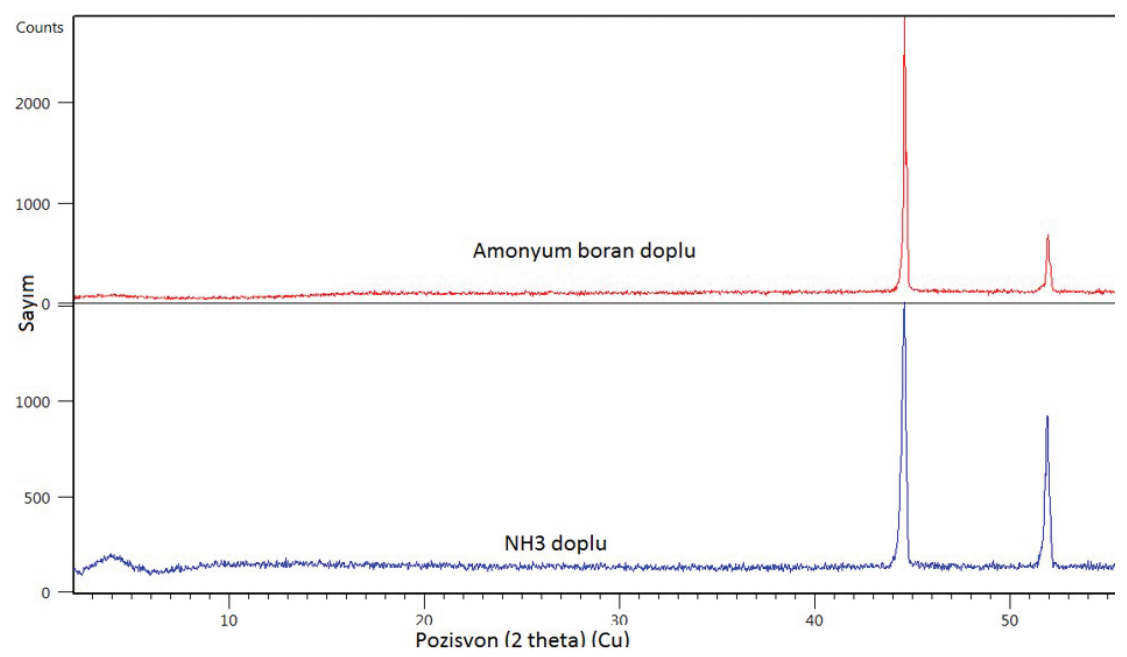

Şekil 3. Nikel köpük üzerinde büyütülen, 20 dakika $\mathrm{NH}_{3}$ gazı ve amonyum boran doplanmış grafen örneklerin X-ray analizleri (X-ray analysis for graphene grown on nickel foam for 20 minutes under NH3 and dopped with ammonia borane). 


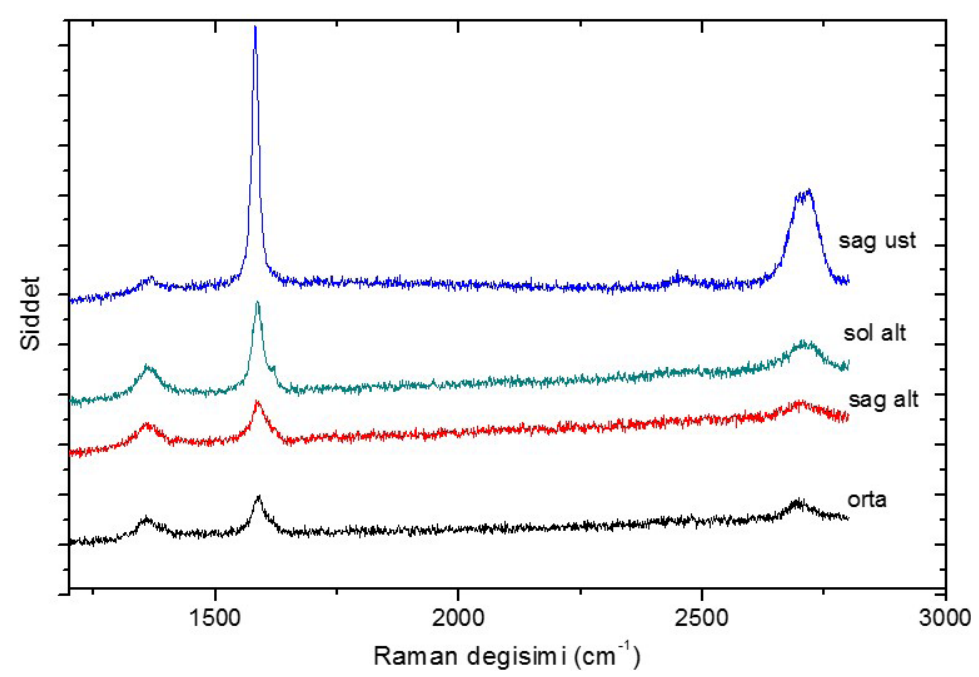

Şekil 4. $1000^{\circ} \mathrm{C}$ 'de 10 dakika büyütülmüş ve amonyum boran ile 25 dakika doplanmış grafen Raman analizi (Raman analysis for graphene grown at $1000^{\circ} \mathrm{C}$ for 10 minutes and doped for 25 minutes in ammonia borane)

Amonyum boran ile doplu örnekler için elde edilen Raman sonuçları Şekil 4'te verilmiştir.

Raman spektroskopisi tipik grafen özelliklerini taşımakta, farklı yüzey noktalarında farklı oranlarda $G$ ve 2D pikleri oluşmuştur. Bu, sistemde homojen olarak grafen oluşumunun gerçekleşmeyebileceğini göstermektedir. Farklı şartlarda B-doplanmış örneklerin XPS analizleri Şekil 5 ve 6'da verilmiştir. $1000^{\circ} \mathrm{C}$ 'de 10 dakika büyütülmüş grafen üzerinde amonyum boran ile 25 dakika doplanmış yapıda \%30 B, \%25 N piki görülmektedir. Azot doplama amonyum boran yapısındaki N sayesinde gerçekleşmiştir. Benzer grafen yapı önce amonyak ile doplanıp ardından amonyum boran ile doplandığında benzer B yüzdeleri elde edilmekle birlikte N, \%5'ler seviyesine gerilemiştir. Doplamanın $1000^{\circ} \mathrm{C}$ yerine $500^{\circ} \mathrm{C}$ 'de gerçekleştirilmesinin buna sebep olabileceği sonucuna ulaşılmıştır.

Elektrokimyasal karakterizasyon için bor doplu örneklerin yarı-hücre testlerinde RDE ölçümleri yapılmıştır. Azot-bor doplu grafen, elektrot olarak 0,1 $\mathrm{M} \mathrm{HClO}_{4}$

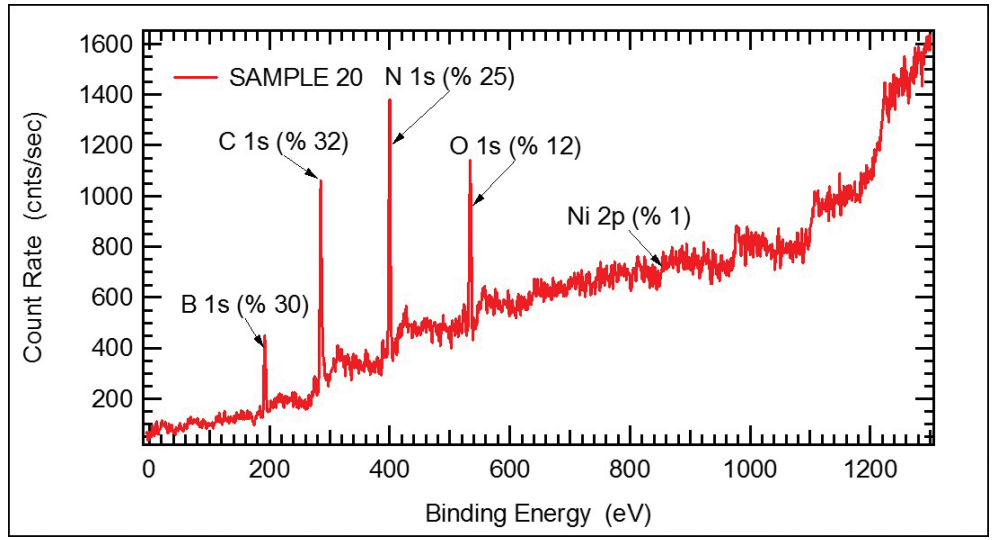

Şekil 5. $1000^{\circ} \mathrm{C}$ 'de 10 dakika büyütülmüş ve amonyum boran ile 25 dakika doplanmış grafen XPS analizi (XPS analysis for graphene grown at $1000^{\circ} \mathrm{C}$ for 10 minutes and doped for 25 minutes in ammonia borane).

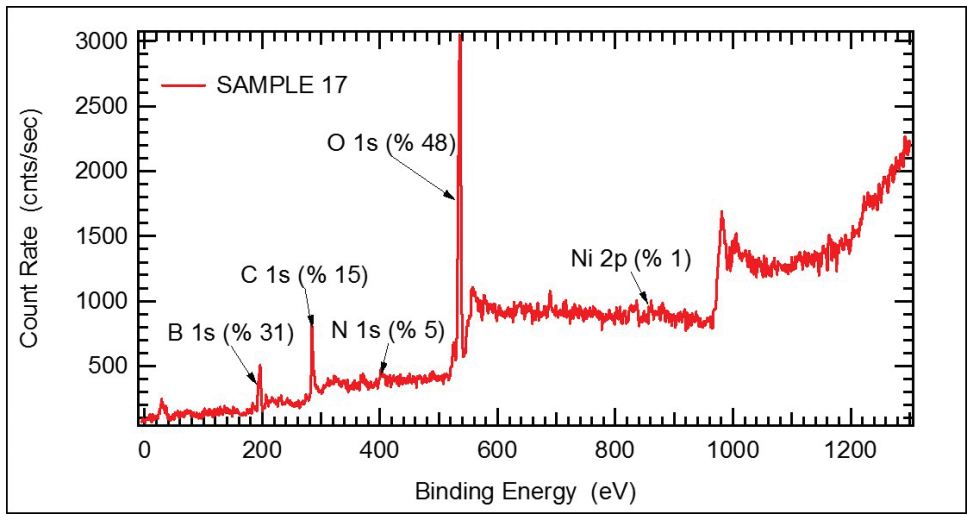

Şekil 6. $500^{\circ} \mathrm{C}$ de 5 dakika $\mathrm{NH}_{3}$ doplanmış ve $400^{\circ} \mathrm{C}$ 'de 30 dakika amonyum boran doplanmış grafen XPS analizi (XPS analysis for graphene dopped at $500^{\circ} \mathrm{C}$ for 5 minutes in $\mathrm{NH}_{3}$ and doped at $400 \mathrm{oC}$ for 30 minutes in ammonia borane). 


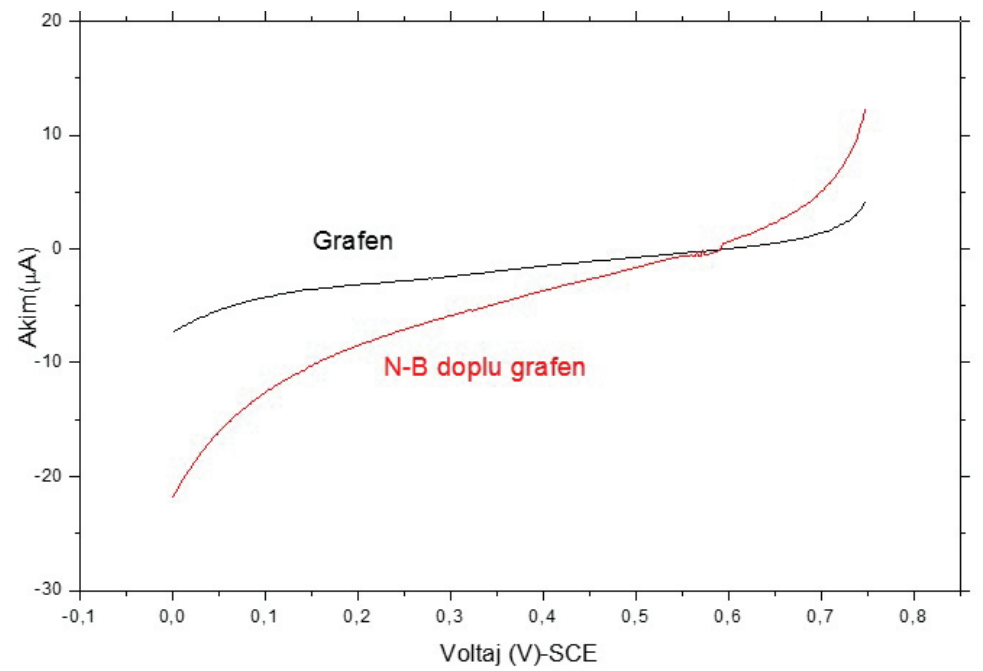

Şekil 7. Grafen ve bor doplu grafen örneklerin oksijen indirgeme grafikleri (Oxygen reduction graphics for plain graphene and boron-doped graphene).

elektrolit içerisinde test edilmiş ve grafen elektrot ile karşılaştırılmıştır (Şekil 7). Herhangi bir metal katalizör olmadan yapısında bor bulunan grafen, saf grafene göre daha yüksek akım vermiştir. Ancak, farklılıklar elektro-katalitik etkiye nazaran oldukça düşüktür.

Ayrıca, katalizör tuzlarının grafen üzerinde indirgenmesi yaklaşımının parçası ve borun elektrot yapısına farklı yöntemlerle etkisini araştırmak amaçlı olarak $\mathrm{NaBH}_{4}$ ile indirgenme yöntemi, aminler ile indirgeme yöntemi ile karşılaştırılmıştır. Grafen büyütmeyi takiben nikel yapıdan tamamen uzaklaştırılmakta, ardından metal tuzu grafen yapısı bozulmadan, $\mathrm{NaBH}_{4}$ ile indirgenerek yükleme yapılmaktadır. Şekil 8'de grafen yüzey üzerine $\mathrm{NaBH}_{4}$ ile indirgenmiş $\mathrm{H}_{2} \mathrm{PtCl}_{6} \cdot 6 \mathrm{H}_{2} \mathrm{O}$ için farklı büyütmelerde yüzey, parçacık boyutları ve elemental analizi gösterilmiştir. Elektrot yapısında \%25'ler seviyesinde bor bulunmaktadır.

Şekil 9'da farklı indirgeme metotları ile elde edilen PtCo katalizörün yakıt pili polarizasyon eğrileri verilmiştir. Açık devre voltajdan başlayarak (yaklaşık 1 volt) her $100 \mathrm{mV}$ polarizasyonda elde edilen akım değerleri kaydedilmiştir. PtCo katalizör ile oluşturulan alaşım yapısında, grafen üzerinde PtCo parçacıkların sodyum borhidrür ile indirgenmesinde daha iyi dağılmış ve aktif alanının artmasından dolayı yüksek performans değerlerine ulaşılmıştır.
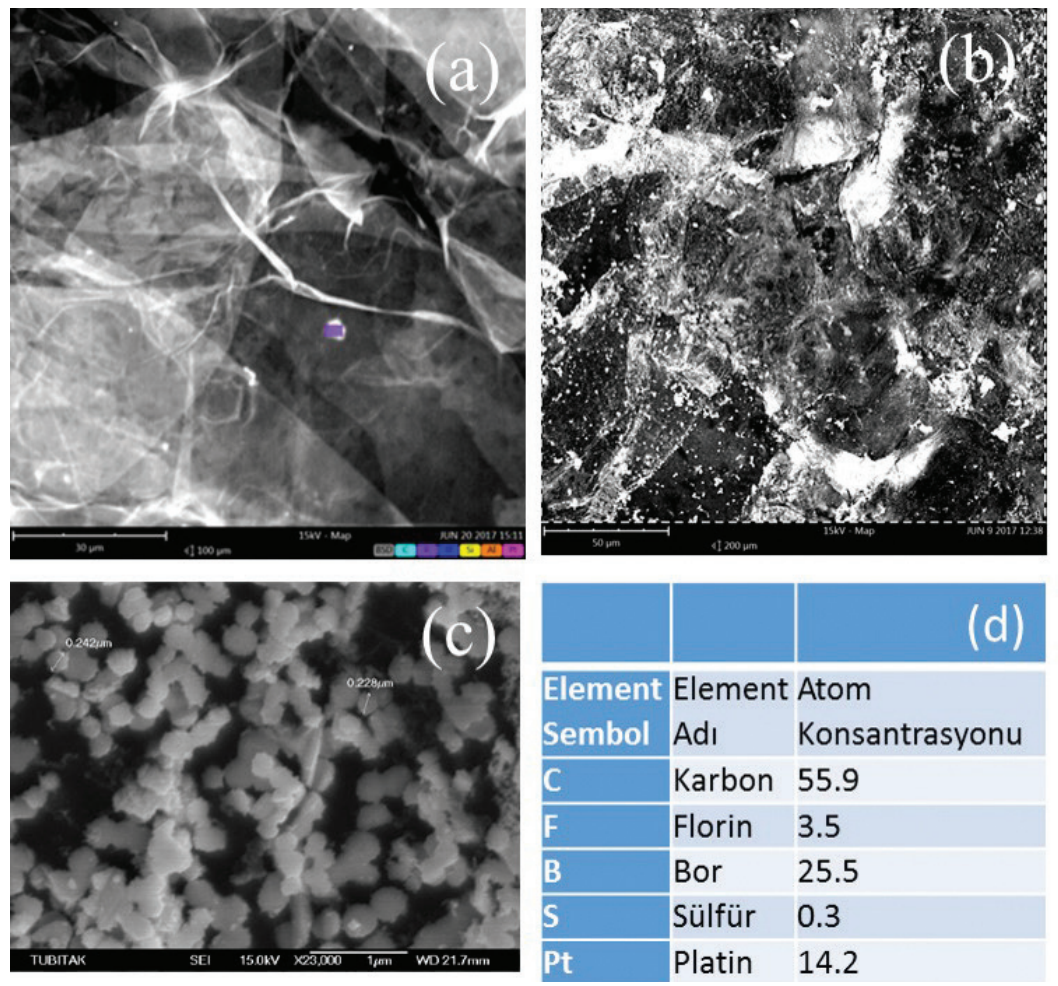

Şekil 8. (a) $\mathrm{NaBH}_{4}$ ile platinsiz, (b,c) Pt tuzu indirgenmiş grafen yüzeyler ve (d) EDX analizleri (Surfaces of graphene without platinum (a) and with $\mathrm{NaBH} 4$ reduced Pt-salts (b,c) and EDX analysis (d)). 


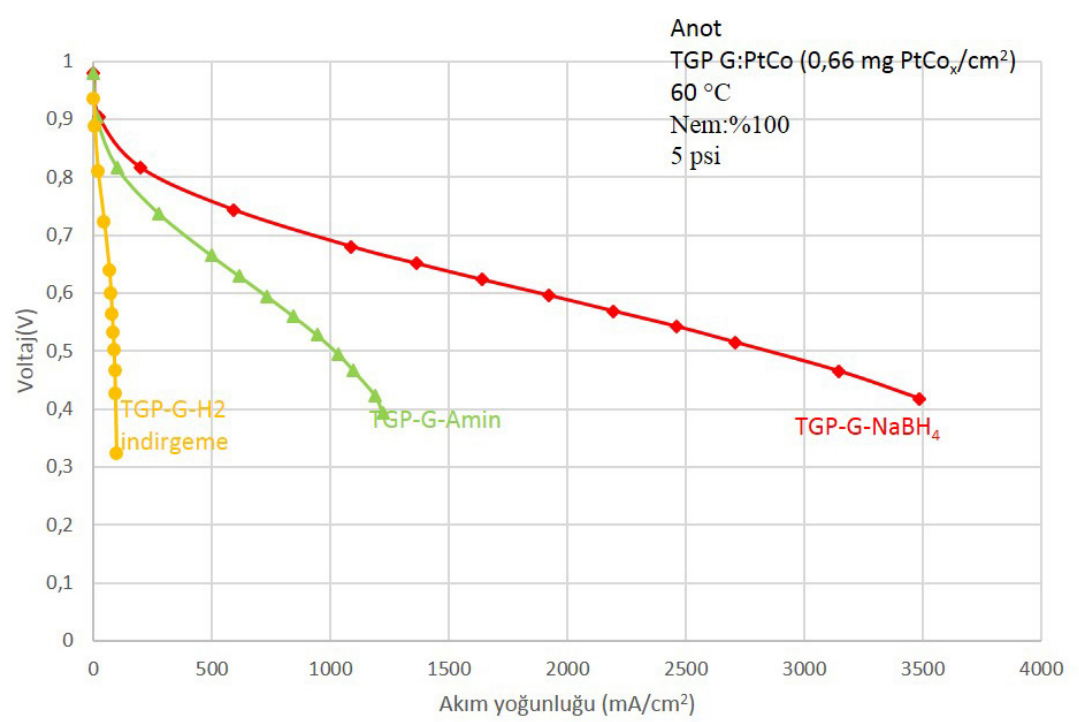

Şekil 9. TGP GDL üzerinde grafen/katalizör için farklı indirgeme yaklaşımlarının (hidrojen ile $800^{\circ} \mathrm{C}$ : TGP-G-H ${ }_{2}$; etilendiamin ile: TGP-G-Amin; sodyum borhidrür ile: TGP-G-NaBH ${ }_{4}$ ) performansa etkisi (Performance effect of different reducing approaches

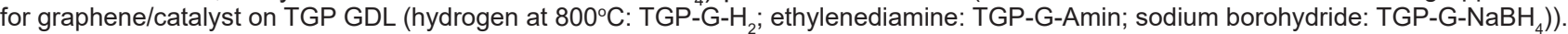

\section{Sonuçların (Conclusions)}

Yapılan çalışmalar ile amonyum boran başarılı bir şekilde yüksek sıcaklıklarda grafen örneklerin bor doplamasında kullanıımış ve değişik analitik yöntemlerle yapıda bor olduğu gösterilmiştir. XPS ve ICP analizleri açık olarak grafen yapıda bor olduğunu gösterirken, Raman analizlerinde borlu ve borsuz örnekler arasında ölçülebilir bir fark gözlemlenmemiştir. Çalışmada ayrıca farklı karbon destekler üzerinde $\mathrm{Pt} / \mathrm{C}$ ve $\mathrm{PtCo}$ katalizörler $\mathrm{NaBH}_{4}$ ile yapılan indirgeme ile üretildikten sonra bor-doplu elektrot olarak kullanıımıştır. Nafyon membranın kullanıldığı yakıt pili testlerinde en iyi performansın $\left(2700 \mathrm{~mA} / \mathrm{cm}^{2} @ 0,5 \mathrm{~V}\right)$ sodyum borhidrür varlığında hazırlanan katalizörler ile elde edildiği görülmüştür. Bu değerler, literatürde verilen güç değerlerinden daha yüksek olup, $\mathrm{PtCo} / \mathrm{B} /$ grafen yapıların $\mathrm{Pt} / \mathrm{B} /$ grafen yapılardan daha iyi elektro katalitik etkiye sahip olduğunu göstermektedir.

\section{Teşekkür (Acknowledgement)}

"1003-Öncelikli Alanlar Ar-Ge Projeleri Destekleme Programı" kapsamında yürütülen 215M302 kodlu proje TUBITAK tarafından desteklenmiştir.

\section{Kaynaklar (References)}

[1] Rao C. N. R., Gopalakrishnan K., Govindaraj A., Synthesis, properties and applications of graphene doped with boron, nitrogen and other elements, Nano Today, 9, 324-343, 2014.

[2] Wang H., Maiyalagan T., Wang X., Review on recent progress in nitrogen-doped Graphene: Synthesis, characterization, and its potential applications, Am. Chem. Soc., 2, 781-794, 2012.

[3] Li X. F., Lian K. Y., Liu L., Wu Y., Qiu Q., Jiang J., Deng M., vd, Unraveling the formation mechanism of graphitic nitrogen doping in thermally treated graphene with ammonia, Sci. Rep., 6, 23495, 2016.
[4] Yeh M. H., Li Y. S., Chen G. L., Lin L. Y., Li T.J., Chuang H. M., Hsieh C. Y., vd., Facile synthesis of boron-doped graphene nanosheets with hierarchical microstructure at atmosphere pressure for metal-free electrochemical detection of hydrogen peroxide, Electrochim. Acta, 172, 52-60, 2015.

[5] Zhao Y., Hu C., Hu Y., Cheng H., Shi G., Qu L., A versatile, ultralight, nitrogen-doped graphene framework,. Angew. Chem., 51, 11173-11388, 2012.

[6] Wu X., Wang Y., Yang P., The field emission properties from the pristine/B-doped graphene-C70 composite, Phys. Lett. A., 381 (24), 2004-2009, 2017.

[7] Panchakarla L. S., Govindaraj A., Rao C. N. R., Boron- and nitrogen-doped carbon nanotubes and graphene, Inorg. Chim. Acta, 363, 4163-4174, 2010.

[8] Liao C., Zhang M., Niu L., Zheng Z., Yan F., Highly selective and sensitive glucose sensors based on organic electrochemical transistors with graphene-modified gate electrodes, J. Mater. Chem. B, 1, 3820-3829, 2013.

[9] Agnoli S., Favarob M., Doping graphene with boron: A review of synthesis methods, physicochemical characterization, and emerging applications, Mater. Chem. A, 4, 5002-5025, 2016.

[10] Mazanek V., Matejkova S., Sedmidubsky D., Pumera M., Sofe Z., One step synthesis of B/N co-doped graphene as highly efficient electrocatalyst for oxygen reduction reaction-synergistic effect of impurities, Chem. Eur. J, 928-936, 2017.

[11] Zheng Y., Jiao Y., Ge L., Jaroniec M., Qiao S. Z., Twostep boron and nitrogen doping in graphene for enhanced synergistic catalysis, Angew. Chem., 125, 3192 $-3198,2013$.

[12] Sheng Z. H., Gao H. L., Bao W. J., Wang F. B., Xia $X$. H., Synthesis of boron doped graphene for oxygen reduction reaction in fuel cells, J. Mater. Chem., 22, 390-395, 2012.

[13] Jing L., Ping S., Zhigang N., Weilin X., Recent advances in heteroatom-doped metal-free electrocatalysts 
for highly efficient oxygen reduction reaction, Electrocatalysis, 6, 132-147, 2015.

[14] Dong F., Cai Y., Liu C., Liu J., Qiao J., Heteroatom $(B, N$ and $P$ ) doped porous graphene foams for efficient oxygen reduction reaction electrocatalysis, Int. J. Hydrogen Energy, 43, 12661-12670, 2018.

[15] Han J., Zhang Y., Niu F., Chen T., Liu J., Xu Y., Lowcost and highly efficient metal-free electrocatalysts for oxygen reduction reaction: Environment-friendly threedimensional B, N Co-doped Graphene Aerogels, Electrocatalysis 10, 56-62, 2019.

[16] Sahoo M., Sreena K. P., Vinayan B. P., Ramaprabhu S., Green synthesis of boron doped graphene and its application as high performance anode material in $\mathrm{Li}$ ion battery, Mater. Res. Bull. 61, 383-390, 2015.

[17] Yang L., Jiang S., Zhao Y., Zhu L., Chen S., Wang X., Wu Q., vd., Boron-doped carbon nanotubes as metalfree electrocatalysts for the oxygen reduction reaction, Angew. Chem. In. Ed. 50, 7132, 2011.

[18] Pullamsetty A., Subbiah M., Sundara R., Platinum on boron doped graphene as cathode electrocatalyst for proton exchange membrane fuel cells, Mater. Res. Bull., 40 (32), 10251-10261, 2015.

[19] Yang H. N., Lee D. C., Park K. W., Kim W. J., Platinum/ boron doped graphene intercalated by carbon black for cathode catalyst in proton exchange membrane fuel cell, Energy, 89, 500-510, 2015.

[20] Kepeniene V., Stagniunaite R., Tamasauskaite L., Norkus E., Investigation of the PtCo/graphene and PtCo-
Ru/graphene Catalysts for Oxygen Reduction Reaction, ECS Transactions, 69 (17), 643-650, 2015.

[21] Yang S., Zhang F., Gao C., Xia J., Lu L., Wang Z., A sandwich-like PtCo-graphene/carbon dots/graphene catalyst for efficientmethanol oxidation, J. Electroanal. Chem., 802, 27-32, 2017

[22] Holmes S. M., Balakrishnan P., Kalangi V. S., Zhang X., Hidalgo M. L., Ajayan P. M., Nair R. R., 2D crystals significantly enhance the performance of a working fuel Cell, Adv. Energy Mater., 7, 1601216, 2017.

[23] Yazıcı M. S., Azder M. A., Salihoglu Ö., Boyacı San F. G., CVD grown graphene as catalyst for acid electrolytes, Int. J. Hydrogen Energy., 43, 10710-10716 2018.

[24] Yazıcı M. S., Azder M. A., Salihoglu Ö., Boyazı San F. G., Ultralow Pt loading on CVD graphene for acid electrolytes and PEM fuel cells, Int. J. Hydrogen Energy., 43, 18572-18577 2018.

[25] Golberg D., Bando Y., Han W., Kurashima K., Sato T., Single-walled B-doped carbon, B/N-doped carbon and $\mathrm{BN}$ nanotubes synthesized from single-walled carbon nanotubes through a substitution reaction, Chem. Phys. Lett., 308, 337-342, 1999.

[26] Wang G., Li X., Wang Y., Zheng Z., Dai Z., Qi X., Liu L., vd., interlayer coupling behaviors of boron doped multilayer graphene, J. Phys. Chem. C, 121 (46), 2603426043, 2017.

[27] Sit V., Geanangel R. A., Wendlandt W. W., Thermochimica, Acta 113, 379-382, 1987. 